\title{
Processes Associated with Convection Initiation in the North American Mesoscale Forecast System, Version 3 (NAMv3)
}

\author{
Michael COLBERT \\ Department of Meteorology and Atmospheric Science, The Pennsylvania State University, University Park, and National Weather \\ Service-Weather Forecast Office, State College, Pennsylvania \\ David J. Stensrud, PAul M. Markowski, AND YvetTe P. Richardson \\ Department of Meteorology and Atmospheric Science, The Pennsylvania State University, University Park, Pennsylvania
}

(Manuscript received 17 October 2018, in final form 2 April 2019)

\begin{abstract}
In support of the Next Generation Global Prediction System (NGGPS) project, processes leading to convection initiation in the North American Mesoscale Forecast System, version 3 (NAMv3) are explored. Two severe weather outbreaks-occurring over the southeastern United States on 28 April 2014 and the central Great Plains on 6 May 2015 - are forecast retrospectively using the NAMv3 CONUS (4 km) and Fire Weather $(1.33 \mathrm{~km})$ nests, each with 5-min output. Points of convection initiation are identified, and patterns leading to convection initiation in the model forecasts are determined. Results indicate that in the $30 \mathrm{~min}$ preceding convection initiation at a grid point, upward motion at low levels of the atmosphere enables a parcel to rise to its level of free convection, above which it is accelerated by the buoyancy force. A moist absolutely unstable layer (MAUL) typically is produced at the top of the updraft. However, when strong updrafts are collocated with large vertical gradients of potential temperature and moisture, noisy vertical profiles of temperature, moisture, and hydrometeor concentration develop beneath the rising MAUL. The noisy profiles found in this study are qualitatively similar to those that resulted in NAMv3 failures during simulations of Hurricane Joaquin in 2015. The CM1 cloud model is used to reproduce these noisy profiles, and results indicate that the noise can be mitigated by including explicit vertical diffusion in the model. Left unchecked, the noisy profiles are shown to impact convective storm features such as cold pools, precipitation, updraft helicity intensity and tracks, and the initiation of spurious convection.
\end{abstract}

\section{Introduction}

Operational convection-allowing models (CAMs) have become instrumental tools in forecasting convective and mesoscale weather events, including deep, moist convection (Kain et al. 2006, 2013; Benjamin et al. 2011; Snively and Gallus 2014). CAM forecasts have been shown to provide useful guidance on the mode of convection (Done et al. 2004; Weisman et al. 2008; Kain et al. 2008), improved forecasts of rainfall amounts (Lean et al. 2008; Roberts and Lean 2008; Clark et al. 2009), and reliable guidance on the severe weather threat (Sobash et al. 2011). A number of studies also have explored the ability of CAMs to forecast convection initiation (CI) by comparing CAM rainfall/reflectivity forecasts with rainfall/reflectivity

Corresponding author: Dr. David J. Stensrud, david.stensrud@ psu.edu observations. Results suggest that CAMs forecast the timing of CI with little bias in mean timing, but with timing errors of individual events typically in the \pm 2 -h range and position errors between 38 and $105 \mathrm{~km}$ (Fowle and Roebber 2003; Duda and Gallus 2013; Kain et al. 2013; Burghardt et al. 2014; Burlingame et al. 2017). It is clear that forecasting CI accurately remains a significant forecast challenge.

In this study, we take a different approach and specifically explore the physical processes associated with $\mathrm{CI}$ in the North American Mesoscale Forecast System, version 3 (NAMv3; Janjić et al. 2005). Two severe weather outbreaks are forecast retrospectively using the NAM 4-km CONUS and 1.33-km Fire Weather nests. Output from each of the forecasts is saved at 5-min intervals, providing a unique look into convective processes that occur on time scales shorter than the operational output interval of $1 \mathrm{~h}$. 
In addition to the physical processes associated with CI, these forecasts provide the opportunity to learn more about the erroneous model soundings associated with deep moist convection. As described by Ferrier et al. (2017), the NAMv3 CONUS nest had a tendency to produce "noisy" vertical profiles of temperature and moisture in the presence of strong updrafts. These vertical profiles are characterized by vertically alternating superadiabatic layers and strong temperature inversions. In an extreme case, such as the updrafts associated with Hurricane Joaquin in early October 2015, these unstable vertical profiles caused the model to crash. The NOAA Environmental Modeling Center (EMC) looked extensively into the cause of these noisy profiles, and ultimately developed a routine to stabilize all vertical layers above the boundary layer that have a lapse rate greater than the dry adiabatic lapse rate (Ferrier et al. 2017). These changes were implemented in NAM version 4, which became operational in early 2017.

Although the newly implemented routine eliminates superadiabatic layers in the vicinity of strong updrafts, it would be helpful to understand what leads to these noisy profiles and determine whether or not they could be eliminated using a different approach. Thus, we seek to understand what model factors contribute to these noisy profiles and to find a way to limit or eliminate their occurrence. We also explore the potential impacts on predictions of deep moist convection in model forecasts where the noisy vertical profiles are retained. Data and methods are outlined in section 2 , followed by model results in section 3. Conclusions are found in section 4 .

\section{Data and methods}

The severe weather outbreaks over the southeastern United States on 28 April 2014 and over the southern great plains on 5 May 2015 are selected as case studies for this project. For each case, the NAMv3 CONUS nest and Fire Weather nest are run out $36 \mathrm{~h}$ beginning at 0000 UTC on the day of the outbreak. Although the CONUS nest has a fixed size and location, the Fire Weather nest can be situated anywhere within the CONUS nest. For the two cases studied, the Fire Weather nest is positioned to capture both the initiation and evolution of deep moist convection associated with the severe weather outbreak and thus is placed over a different geographic region for the two cases (Fig. 1). These locations of the Fire Weather nest are not the same as in the operational forecasts of the two days.

The NAM uses the National Centers for Environmental Prediction (NCEP) Nonhydrostatic Multiscale Model on the B Grid (NMMB) dynamic core [for technical details, refer to Janjić et al. (2005), Janjić and
Gall (2012), and NEMS-NMMB (2016)]. There are 60 sigma-pressure vertical levels, with 18 vertical levels in the lowest $1 \mathrm{~km}$ above ground. The vertical levels are terrain following near the surface and gradually stretch and become pressure following at high altitudes, as described by Eckermann (2009). Time differencing in the horizontal uses a second-order Adams-Bashforth noniterative scheme with a slight off-centering for stability, a second-order horizontal advection scheme, horizontal divergence damping, and explicit horizontal diffusion in the form of a second-order Smagorinsky (1963) scheme modified by the value of turbulent kinetic energy (TKE; Janjić 1990). Time differencing in the vertical uses the Crank-Nicolson scheme, a second-order vertical advection scheme, and a vertical turbulence diffusion scheme controlled by the Mellor-Yamada-Janjić turbulence scheme (Janjić 1994). There is no explicit vertical diffusion. The NAM physics includes the Noah land surface model (Ek et al. 2003), the Ferrier-Aligo microphysics scheme (Aligo et al. 2018), and the Rapid Radiative Transfer Model for longwave (Iacono et al. 2008) and shortwave (Mlawer et al. 1997) radiation. The NAM CONUS and Fire Weather nests do not use a shallow convection scheme.

Model reflectivity is used to identify areas of convection in the NAM, following Kain et al. (2013). To distinguish between areas of convection and areas of brightbanding, model reflectivity is interpolated to the height of the $-10^{\circ} \mathrm{C}$ isotherm (Kain et al. 2013). A model reflectivity threshold of $35 \mathrm{dBZ}$ is used to distinguish between convective and nonconvective points (Gremillion and Orville 1999; Roberts and Rutledge 2003; Mecikalski and Bedka 2006; Kain et al. 2013). Grid points are defined as newly convective (NC) when the following conditions are met:

1) Reflectivity on the $-10^{\circ} \mathrm{C}$ isotherm $\left(\operatorname{Ref}_{-10}\right) \geq$ $35 \mathrm{~dB} Z$,

2) Surface-200-hPa column-maximum vertical velocity $\left(w_{\max }\right) \geq 1 \mathrm{~m} \mathrm{~s}^{-1}$,

3) In the preceding $30 \mathrm{~min}$, Ref $_{-10}<35 \mathrm{dBZ}$, and

4) In the following $5 \mathrm{~min}$, some point within 2 horizontal grid lengths $(\Delta)$ in the CONUS nest $(6 \Delta$ in Fire Weather nest) exhibits Ref $_{-10} \geq 35 \mathrm{dBZ}$ and $w_{\max } \geq$ $1 \mathrm{~ms}^{-1}$.

The first three conditions identify grid points where convection is either being initiated or is being advected from the surroundings. The fourth condition necessitates that the convection is persistent for at least two consecutive output times. NC points are further classified as $C I$ points if no points within $4 \Delta$ in the CONUS nest ( $12 \Delta$ in the Fire Weather nest) exhibit a combina-

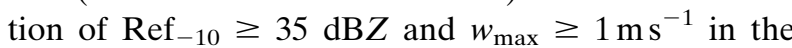




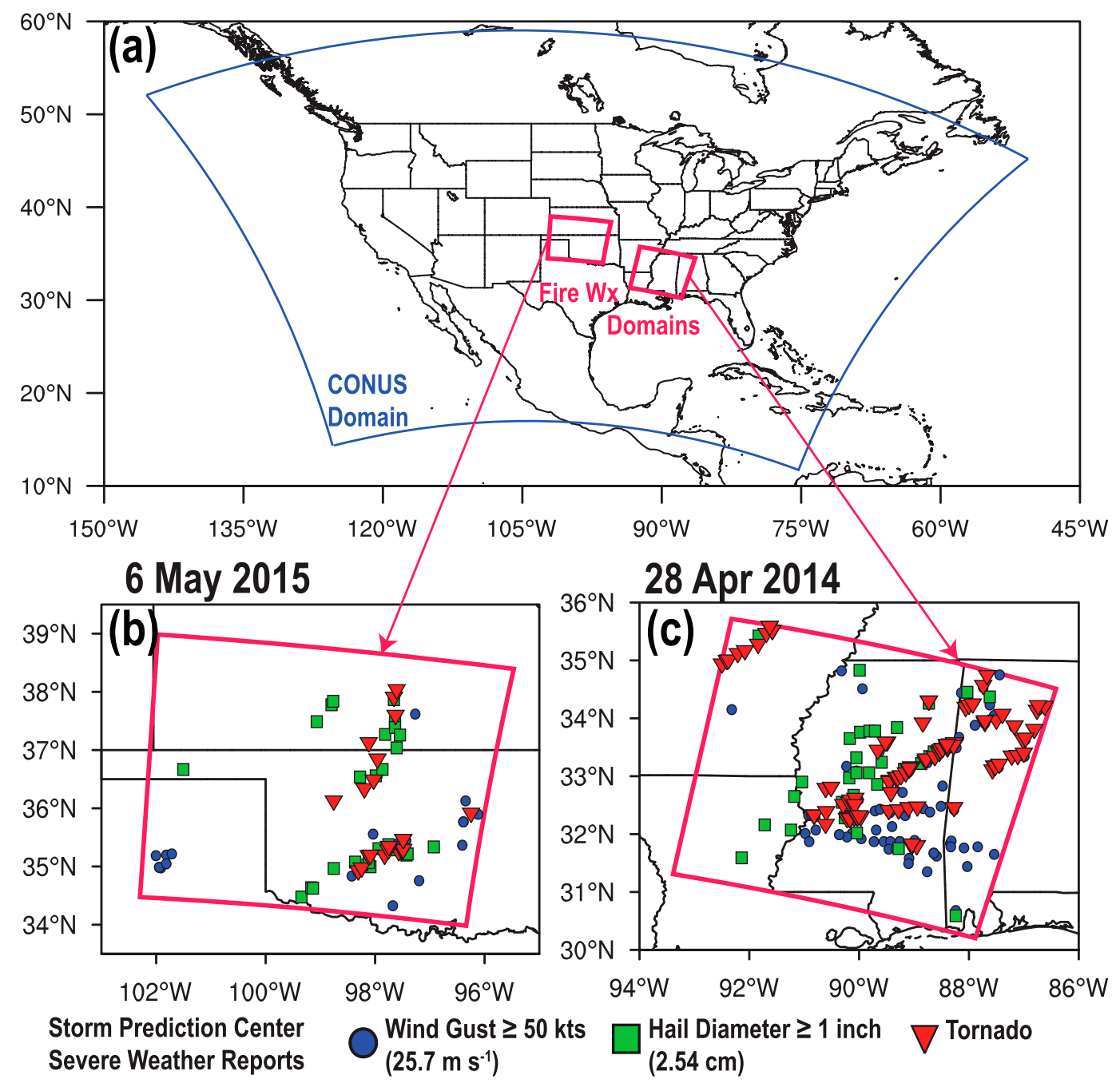

FIG. 1. The (a) NAM 4-km CONUS domain with the locations of the Fire Weather 1.3-km domains for the (b) 6 May 2015 and (c) 28 Apr 2014 cases. Storm reports for both events are shown in (b) and (c) with the report type identified in the legend.

10 min prior to becoming NC. Adding this condition eliminates points where preexisting convection is advected in from the surroundings. Once a set of $\mathrm{NC}$ and CI grid points is created, vertical and horizontal cross sections through the $\mathrm{NC}$ and $\mathrm{CI}$ points, as well as vertical profiles of temperature, moisture, and condensate fields at the $\mathrm{NC}$ and $\mathrm{CI}$ points, are investigated to determine how the model atmosphere evolves in the $45 \mathrm{~min}$ prior to the grid point becoming convectively active. This process is repeated for dozens of NC and CI points, yielding confidence that the resulting evolution diagnosed is robust.

After the processes leading up to convection are explored in the NAM output, Cloud Model 1 (CM1) version 18 (Bryan and Fritsch 2002) is used to explore what factors contribute to the erroneous "noisy" vertical profiles of temperature and moisture that develop in the vicinity of strong updrafts in the NAM. The CM1 is configured to replicate the NAM as closely as possible; however, there are some differences. The vertical grid in CM1 is made up of 60 stretched layers like in the NAM, with 18 levels below $1 \mathrm{~km}$ above ground level; however all levels in CM1 are in height coordinates (not sigma-pressure) and there is no terrain. Time differencing in both the vertical and horizontal in CM1 uses a third-order Runge-Kutta scheme, with a sixth-order advection scheme in both the horizontal and vertical, divergence damping, a Rayleigh damping zone, and sixth-order explicit horizontal and vertical diffusion using a Smagorinsky scheme (Smagorinsky 1963) with the Smagorinsky coefficient set to 0.18 . The CM1 physics includes the Morrison double-moment microphysics scheme 
(Morrison et al. 2005, 2009). CM1 could not be configured to use a TKE-based turbulence diffusion scheme in the vertical while simultaneously using a Smagorinsky explicit diffusion scheme modified by the value of TKE in the horizontal, as done in the NAM. Instead, CM1 simulations are run with both TKE-based turbulence diffusion and Smagorinsky explicit diffusion schemes in the horizontal and vertical, with the ability to turn off the explicit diffusion in either dimension.

Finally, the Advanced Research version 4.0.3 of the Weather Research and Forecasting (WRF) Model (Skamarock et al. 2008) is run on a single idealized supercell thunderstorm case to determine if behaviors similar to those seen in the NAM and CM1 are produced. Time differencing in both the vertical and horizontal in WRF uses a third-order Runge-Kutta scheme, with a fifth-order horizontal advection scheme, a thirdorder vertical advection scheme, divergence damping, a Rayleigh damping zone, and for simplicity a secondorder diffusion scheme with constant diffusion coefficients in the horizontal and vertical (values set to 0.1 times the horizontal grid spacing in meters), and the Morrison double-moment microphysics scheme (Morrison et al. 2005, 2009). Setting the value of the vertical diffusion coefficient to zero allows us to turn off the explicit vertical diffusion for one of the runs.

Initial input soundings for the CM1 runs include soundings taken from grid points in the NAM shortly before they became convectively active, as well as the analytic sounding of Weisman and Klemp (1982, their Fig. 1). The analytic sounding is used with CM1 to determine how much impact explicit vertical diffusion has on a well-behaved and highly studied environment that is favorable for supercells. Differences seen in model runs started from an analytic environment are expected to be amplified in real data situations when the environmental conditions have more vertical structure. The Loftus et al. (2008) method of forced convergence is used to initiate convection in the CM1 simulations, while a warm bubble is used to initiate convection in WRF. The CM1 and WRF simulations are run at both $\Delta=4$ and $1.33 \mathrm{~km}$; results from using different grid spacing are very similar and so only the 4-km grid length results are shown. In each set of runs, the impact of turning the explicit vertical diffusion scheme on or off is tested.

\section{Model results}

\section{a. NAM results}

In the $36 \mathrm{~h}$ between 0000 UTC 28 April and 1200 UTC 29 April 2014, there are 1937 CI points identified in the Fire Weather nest. To more easily display the evolution of the number of CI points as forecast time progresses, a 15 -min centered moving average is applied to the time series. In the Fire Weather nest, the period from 0600 to 1800 UTC 28 April is generally the most active time for CI points, as convection developed ahead of a cold front that enters the Fire Weather domain from the west (Fig. 2a). The primary maximum in CI points is between 0800 and 0900 UTC 28 April, during which time convective cells develop and ultimately merge into a quasilinear convective system (QLCS). A secondary maximum occurs in the late morning hours, around 1500 UTC 28 April, as convection develops in the wake of the QLCS, which, by this time, has decayed. The convection that eventually becomes the primary producer of severe weather develops toward the end of the active CI period, between 1700 and 1800 UTC. After 1800 UTC, there is a decrease in quantity of CI points and convection instead grows upscale from ordinary cells into supercells and a QLCS. There is, however, one more maximum in CI points between 0100 and 0700 UTC 29 April, as new convection develops along the cold front as it approached the Gulf Coast.

In the CONUS forecast of the 28 April 2014 case, the CI points shown (Fig. 2c) are only for the geographic region that overlaps with the Fire Weather nest. This allows for a comparison of $\mathrm{CI}$ behavior on the two nests. As the CONUS nest has 9 times fewer grid points than the Fire Weather nest, the number of CI points on the CONUS nest is fewer. Yet results from the CONUS nest show a very similar behavior in the moving average number of CI points through time when compared to the Fire Weather nest (Fig. 2a), as the period between 0600 and 1800 UTC 28 April remains the most active time for CI points. Thus, the evolution of CI events within the two nests is quite similar.

Compared to the April case, the $36 \mathrm{~h}$ between 0000 UTC 6 May and 1200 UTC 7 May 2015 are less active within the Fire Weather and CONUS nest simulations (Figs. 2b,d), with $37 \%$ fewer total CI points in the Fire Weather nest on this day (i.e., 1213 CI points). In both the CONUS and Fire Weather simulations, the most active time for CI points is in the first few hours, as convection develops in northern Texas during the model spinup time (Fig. 2b). There is a secondary maximum in CI activity between 1900 and 2300 UTC 6 May as convection develops just east of a dryline during peak afternoon heating.

Although there are thousands of CI points identified in each nest and in each forecast, CI points make up just a small fraction of the NC points (Fig. 3). In the Fire Weather forecasts, CI points make up just $0.67 \%$ of all $\mathrm{NC}$ points. CI points are such a small fraction of NC points because a convective storm can only produce $\mathrm{CI}$ 


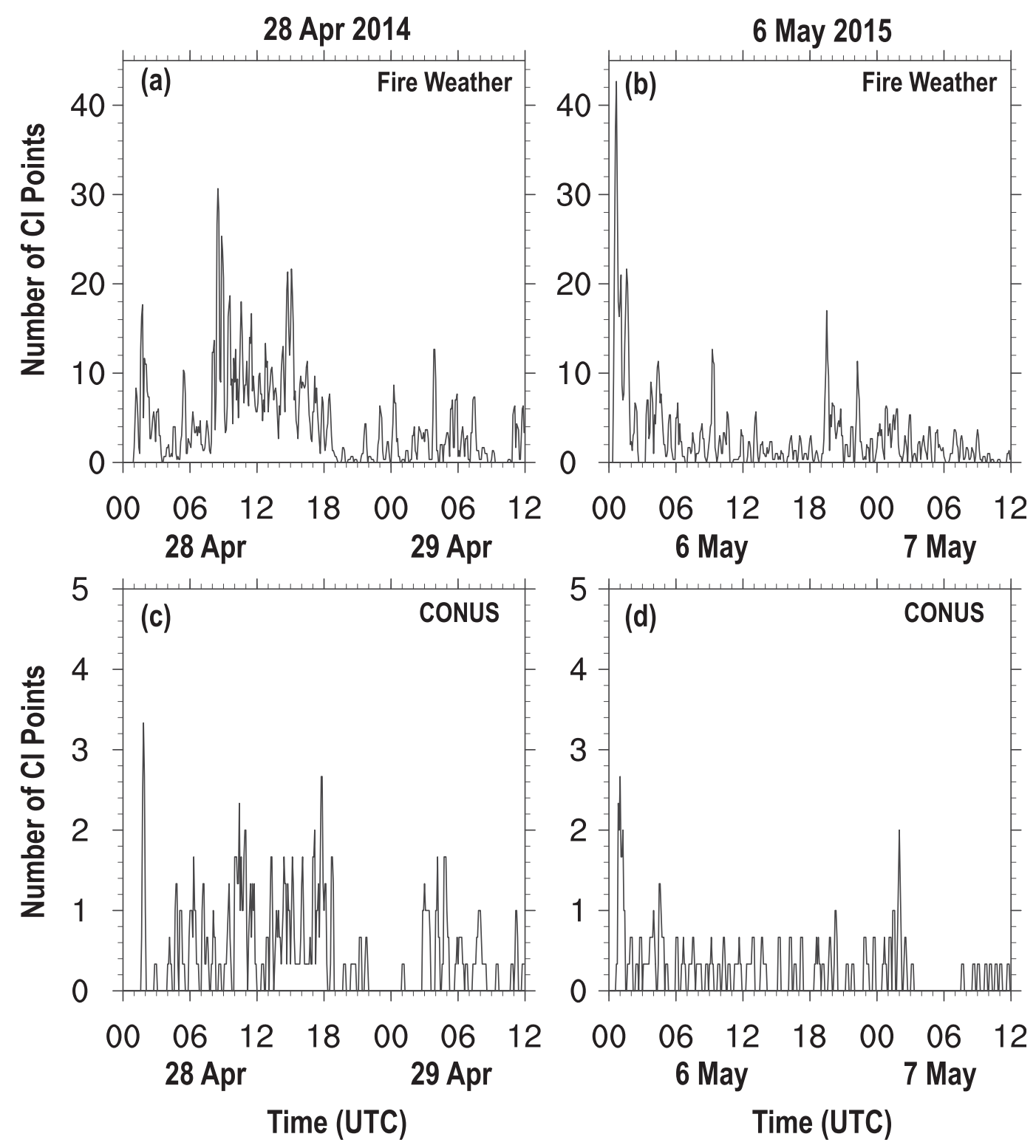

FIG. 2. Centered 15-min moving averages of the number of CI points within the (a),(b) Fire Weather nest and (c),(d) portion of CONUS nest domains covering the same geographic region as the Fire Weather nest during the (left) 28 Apr 2014 and (right) 6 May 2015 NAMv3 forecasts.

points at the first time step of its lifetime, and at that time, it is generally smallest in size. Once a storm forms it can be advected into new grid points, which become NC points, but subsequent CI points must be sufficiently far away from preexisting convection. Of course, the instantaneous fraction of NC points that are also CI points can be much higher than $1 \%-3 \%$, especially at the onset of a period of convection.

Dozens of points from the NC and CI groups, including both surface-based and elevated CI, are examined to see how a grid point becomes convectively active in the NAM. While the air parcels that lead to CI are not stationary, we assume stationarity and use an Eulerian perspective to evaluate the model results and focus upon evolution at individual grid points. In general, the results are similar for both NC and CI points, for both surfacebased and elevated CI, and for points from both the CONUS and Fire Weather nests. A representative example of the evolution of a grid point from nonconvective to convectively active is shown from the CONUS nest (Fig. 4). In the 15-45 min leading up to a grid point becoming convectively active, an area of weak upward motion (typically $<1 \mathrm{~m} \mathrm{~s}^{-1}$ ) develops in the lowest few kilometers above ground level (Figs. 4a,d). As this area 


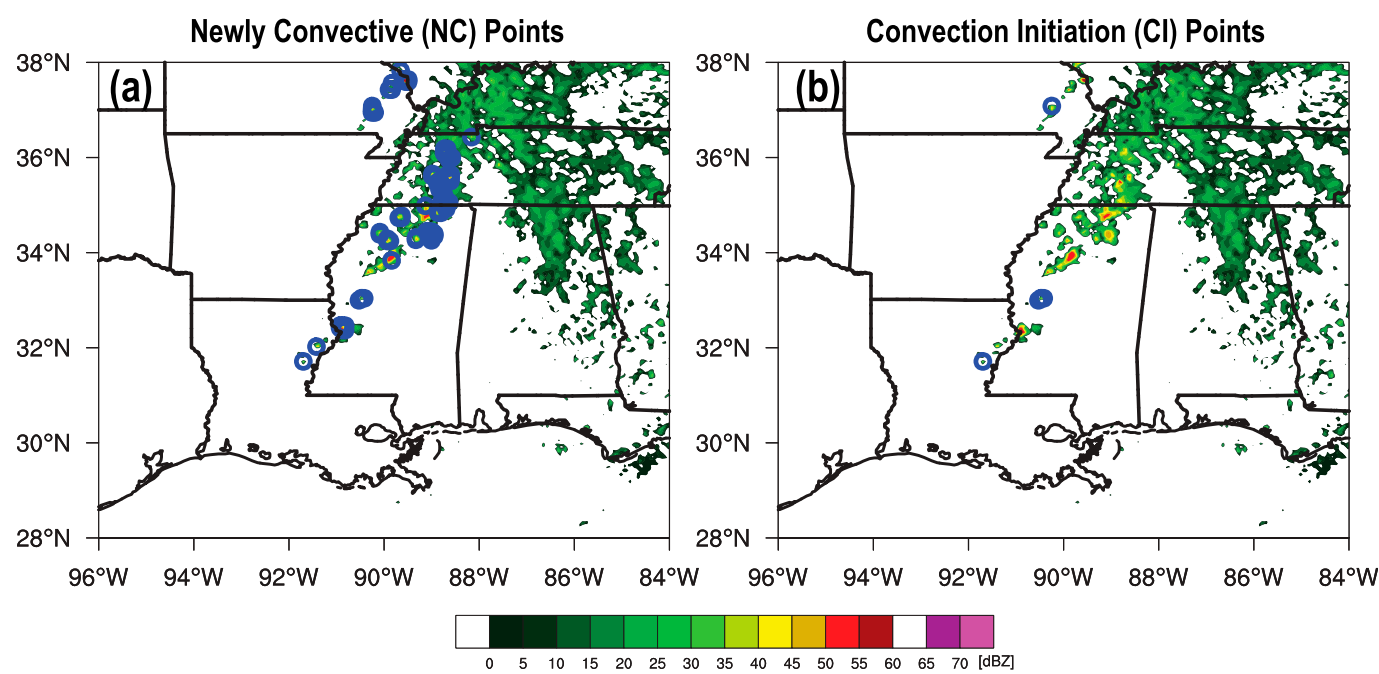

FIG. 3. (a) Instantaneous NC and (b) CI points (blue circles) at 1845 UTC 29 Apr 2014 diagnosed from the CONUS nest. The Ref ${ }_{-10 \mathrm{C}}$ field is shaded as indicated.

of rising motion persists, the depth of the vertical profile that is saturated increases (Figs. 4c,f,i). A positive temperature perturbation develops just above the planetary boundary layer (PBL), or in the case of elevated convection, above a warm nose, and subsequently continues to rise up through a layer of conditional instability (Figs. 4f,i). At the same time, the layer of upward motion grows taller and more intense (Figs. 4g,j). The warm perturbation often modifies the stability of the profile by producing a moist absolutely unstable layer (MAUL; Bryan and Fritsch 2000) above it (Figs. 4f,i,l) in which a saturated layer of air has a lapse rate greater than moist adiabatic. This MAUL rises up through the free troposphere at speeds ranging from $2-12 \mathrm{~m} \mathrm{~s}^{-1}$, and a deep column of condensate is produced below it (Figs. 4h,k). This model behavior is consistent with the observations of Ziegler and Rasmussen (1998) and Lock and Houston (2014), who indicate that mesoscale upward motion is a key factor in CI.

In many instances, the temperature and moisture profiles below the initial MAUL become "noisy," taking on structures that are likely attributable to numerical waves (Figs. 4i,l), like those described by Ferrier et al. (2017). These numerical waves tend to develop when large vertical gradients of equivalent potential temperature $\theta_{e}$ are collocated with updrafts in excess of $1 \mathrm{~m} \mathrm{~s}^{-1}$. As the MAUL moves upward, numerical waves propagate downward from below the MAUL toward the PBL. Within the numerical waves, $\theta_{e}$ fluctuates from anomalously large to anomalously small values (Fig. 4l). These $\theta_{e}$ anomalies can be as large as $6^{\circ} \mathrm{C}$ warmer or colder than the values of $\theta_{e}$ along the moist adiabat that represents the rising parcel. Strong vertical gradients also develop in the condensate field (Fig. 4k), although the vertical momentum field remains smooth as the waves develop (Fig. 4j).

Alternating warm and cold temperature perturbations are seen moving upward within the updrafts associated with the noisy CI grid points (Fig. 5). At the time of $\mathrm{CI}$ and $15 \mathrm{~min}$ later, a horizontal component to the numerical waves is evident in the $\theta_{e}$ field, with a "staggered" vertical appearance to the warm and cold anomalies (Figs. 5e,f,g,h). This numerical wave structure also can be seen in the vertical cross section of the vertical velocity at 15 min after CI (Figs. $5 \mathrm{~g}, \mathrm{~h}$ ).

A representative CI point from the Fire Weather nest located about $40 \mathrm{~km}$ south of Woodward, Oklahoma, with CI at 2220 UTC 6 May 2015 has an evolution prior to CI (Fig. 6) similar to that seen from the CONUS nest. The winds throughout the troposphere are strong at this location, so only the period from $-10 \mathrm{~min}$ prior to $\mathrm{CI}$ to 5 min after the time of CI are presented, as the convection quickly moves away from this location. The values of $\theta_{e}$ fluctuate from anomalously large to anomalously small values along the moist adiabat below the MAUL (Figs. 6i,l), just as seen on the CONUS nest. Although the horizontal scale is reduced, owing to the smaller horizontal grid size, the staggered vertical appearance to the warm and cold temperature perturbations is present (Figs. 7e,f,g,h). These characteristic structures are observed at all of the dozens of CI points explored, albeit with some variations in the magnitude of the $\theta_{e}$ fluctuations and the vertical staggering of features.

\section{b. CM1 results}

In an effort to reproduce the noisy soundings observed in the NAM forecasts in association with CI, the 
Vertical Velocity $\left(\mathrm{m} \mathrm{s}^{-1}\right)$
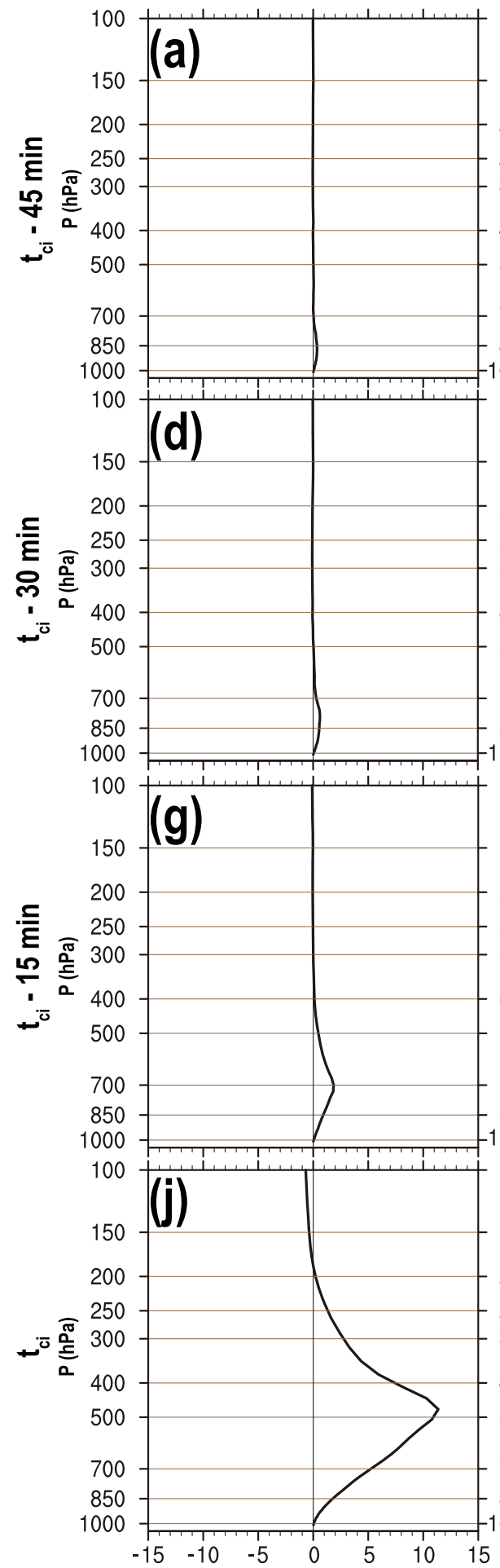

Total Condensate $\left(\mathrm{g} \mathrm{kg}^{-1}\right) \quad$ Temp and Dewpoint $\left({ }^{\circ} \mathrm{C}\right)$
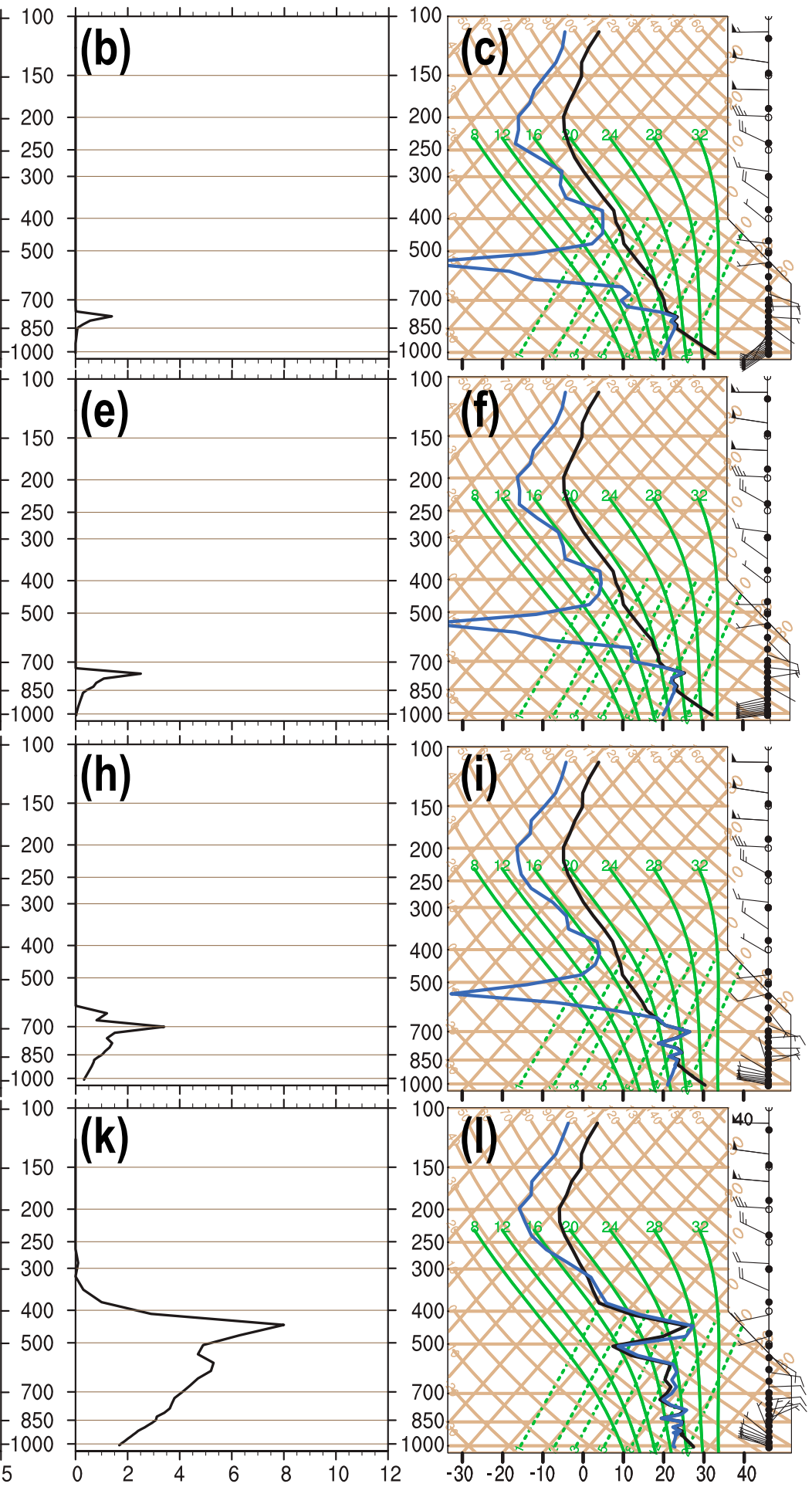

FIG. 4. Vertical profiles of (left) vertical velocity, (center) total cloud condensate, and (right) temperature (black) and dewpoint (blue) from a CONUS nest CI point in southern Florida on $28 \mathrm{Apr} 2014$ at (a)-(c) $t_{\mathrm{CI}}-45 \mathrm{~min}$, (d) - (f) $t_{\mathrm{CI}}-30 \mathrm{~min}$, (g)-(i) $t_{\mathrm{CI}}-15 \mathrm{~min}$, and (j)-(l) $t_{\mathrm{CI}}$, where $t_{\mathrm{CI}}$ is the time of convection initiation at $2200 \mathrm{UTC}$. 


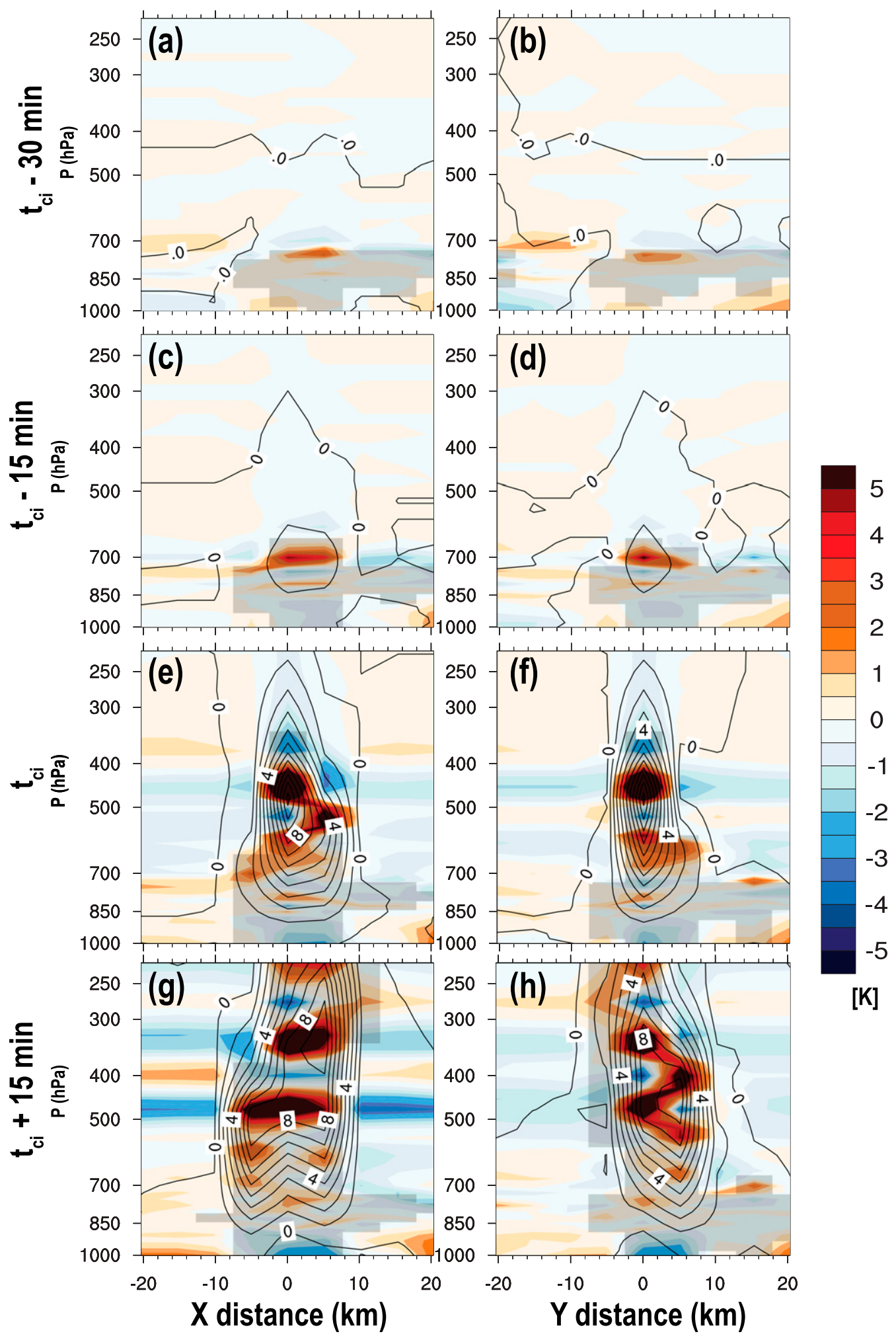

FIG. 5. The (left) $X$ and (right) $Y$ cross sections through the CONUS nest CI point at (a),(b) CI $-30 \mathrm{~min}$, (c),(d) CI - $15 \mathrm{~min},(\mathrm{e})$,(f) at the time of CI, and (g),(h) $15 \mathrm{~min}$ past the time of CI. Red-blue shading is $\theta^{\prime}$, vertical velocity $w$ is contoured every $1 \mathrm{~m} \mathrm{~s}^{-1}$, and gray shading is total cloud condensate $>0.001 \mathrm{~kg} \mathrm{~kg}^{-1}$. 


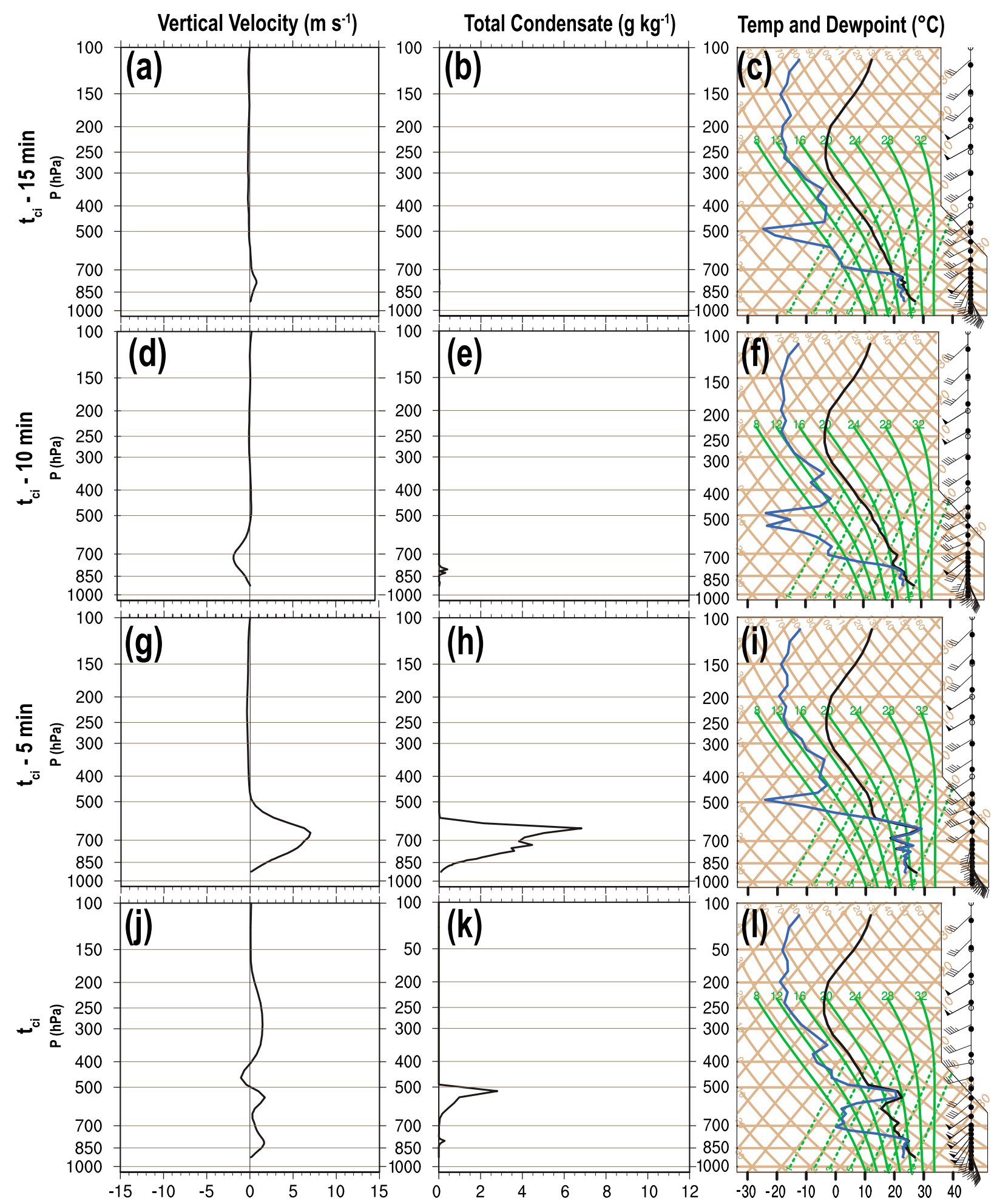

FIG. 6. Vertical profiles of (left) vertical velocity, (center) total cloud condensate, and (right) temperature (black) and dewpoint (blue) from a Fire Weather nest CI point located $40 \mathrm{~km}$ south of Woodward, Oklahoma, on 6 May 2015 at (a) $-(\mathrm{c}) t_{\mathrm{CI}}-15 \mathrm{~min}$, (d)-(f) $t_{\mathrm{CI}}-10 \mathrm{~min},(\mathrm{~g})-(\mathrm{i}) t_{\mathrm{CI}}-5 \mathrm{~min}$, and (j)-(l) $t_{\mathrm{CI}}$, where $t_{\mathrm{CI}}$ is the time of convection initiation at 2220 UTC. 

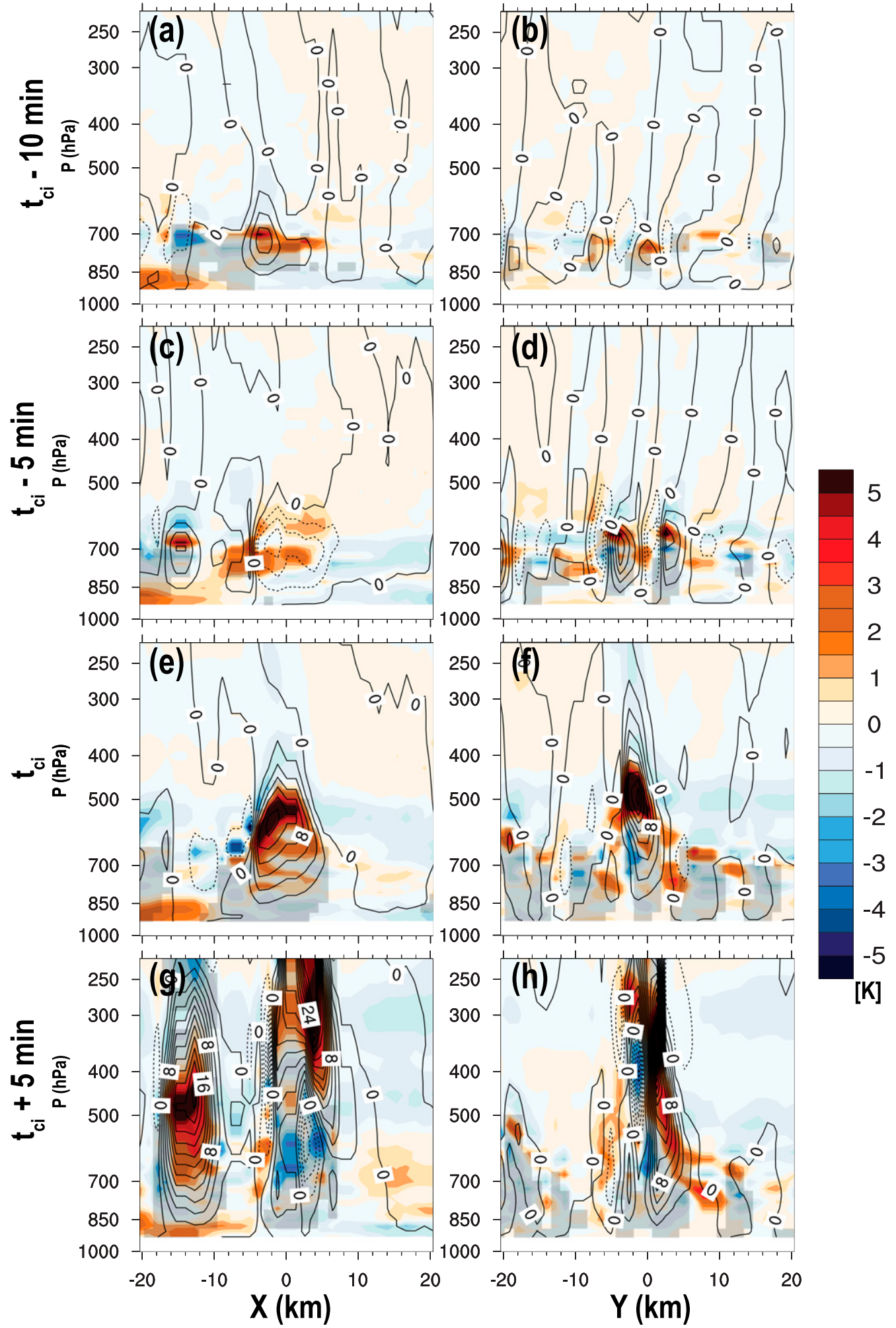

FIG. 7. The (left) $X$ and (right) $Y$ cross sections through the Fire Weather CI point at (a),(b) CI $-10 \mathrm{~min}$, (c),(d) CI $-5 \mathrm{~min}$, (e),(f) at the time of CI, and (g),(h) 5 min past the time of CI. Red-blue shading is $\theta^{\prime}$, vertical velocity $w$ is contoured every $1 \mathrm{~m} \mathrm{~s}^{-1}$, and gray shading is total cloud condensate $>0.001 \mathrm{~kg} \mathrm{~kg}^{-1}$. 


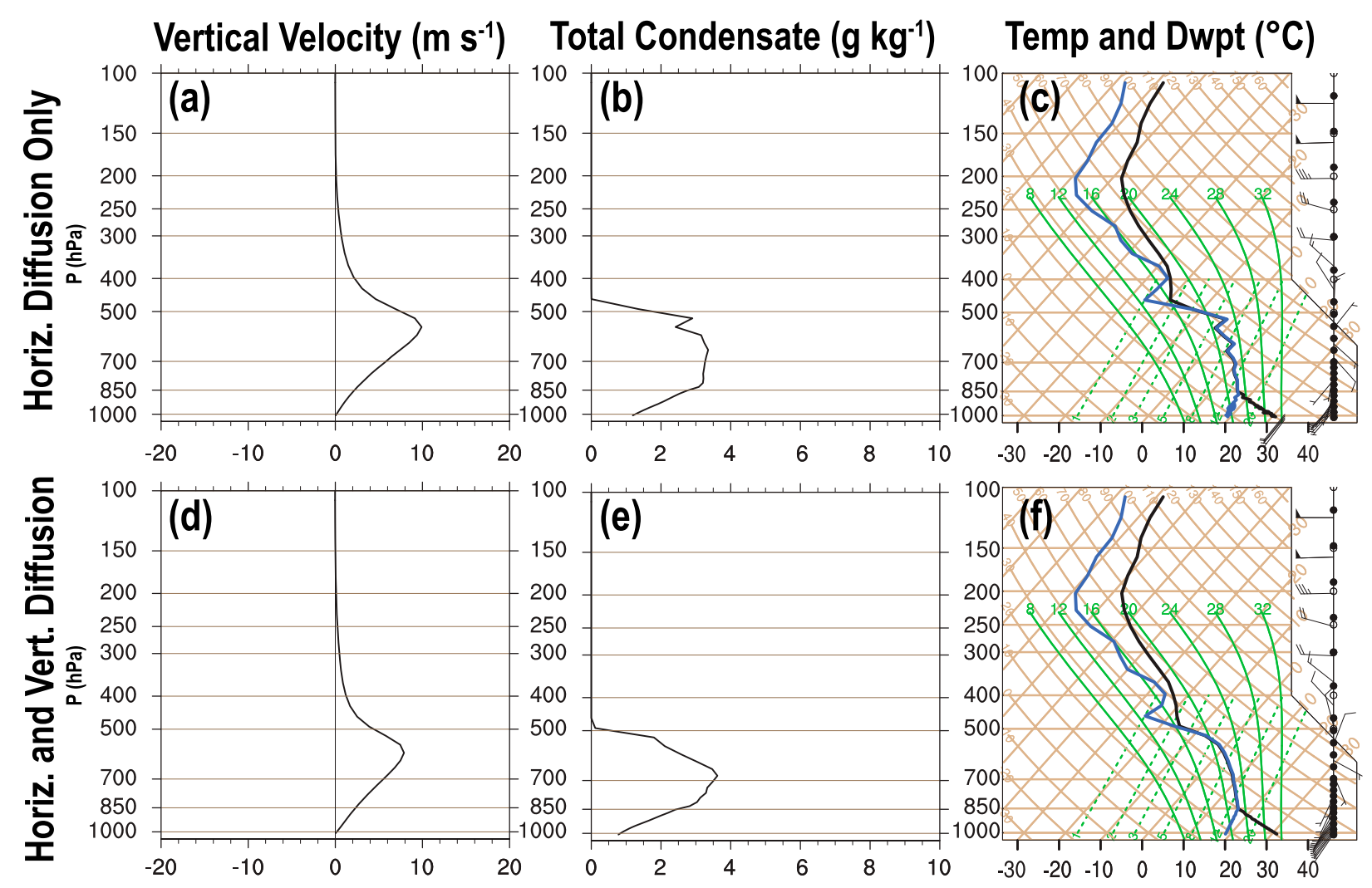

FIG. 8. (left) Vertical velocity, (center) total condensate, and (right) temperature and humidity profiles at the time of CI for the (a)-(c) explicit horizontal diffusion only and (d)-(f) explicit horizontal and vertical diffusion CM1 simulations of the NAM CONUS CI point in southern Florida.

NAM CONUS nest sounding from the aforementioned point in Florida at $40 \mathrm{~min}$ prior to $\mathrm{CI}$ is used as the initial thermodynamic and vertical wind profile in CM1. The weak winds in the vertical profile make the Florida CI point desirable because CI essentially occurred in situ at this point. Smagorinsky explicit horizontal diffusion is used in one CM1 simulation, and both explicit horizontal and explicit vertical diffusion are used in the other CM1 run. The simulations are run forward $4 \mathrm{~h}$, with Coriolis applied to the perturbation winds.

In the CM1 simulation with no explicit vertical diffusion, the evolution of the vertical thermodynamic profile leading up to CI resembles that seen in the NAM (Figs. 8a-c). As forced convergence from the Loftus et al. (2008) method provides weak upward motion at low levels, the sounding becomes saturated and parcels are lifted above their LFC. As the MAUL rises upward within the first $15 \mathrm{~min}$ of the simulation, numerical waves develop below the MAUL and propagate downward, eventually entering the PBL. While the evolution of the sounding structures is very similar between the NAM and CM1, the noisy profiles are not identical between the two models; the CM1 $\theta_{e}$ anomalies between the highest-altitude MAUL and the top of the PBL are smaller in magnitude (just a few degrees Celsius) compared to the NAM, while the waves within the PBL itself are more pronounced in CM1 (cf. Figs. 41 and 8c). The smaller wave amplitudes in CM1 below the MAUL and above the PBL top may be due to the different numerics used in CM1 as compared to the NAM. The larger wave amplitudes in the PBL may be a result of CM1 not having a PBL turbulence diffusion scheme in the simulation without explicit vertical diffusion, whereas MYJ PBL turbulence diffusion is used in the NAM.

When Smagorinsky explicit diffusion is applied in both the horizontal and vertical, the numerical waves disappear entirely from the vertical profile (Figs. 8d-f). A MAUL still develops within the upper part of the updraft, but the erroneous $\theta_{e}$ anomalies do not form beneath it. It is encouraging that the addition of explicit vertical diffusion still allows for the presence of a MAUL at the top of the updraft, as seen in other studies (Lane et al. 2003). Adding explicit vertical diffusion reduces the maximum vertical velocity within the updraft by about $20 \%$ and limits the rate at which condensate forms in the midlevels. The vertical profile of 


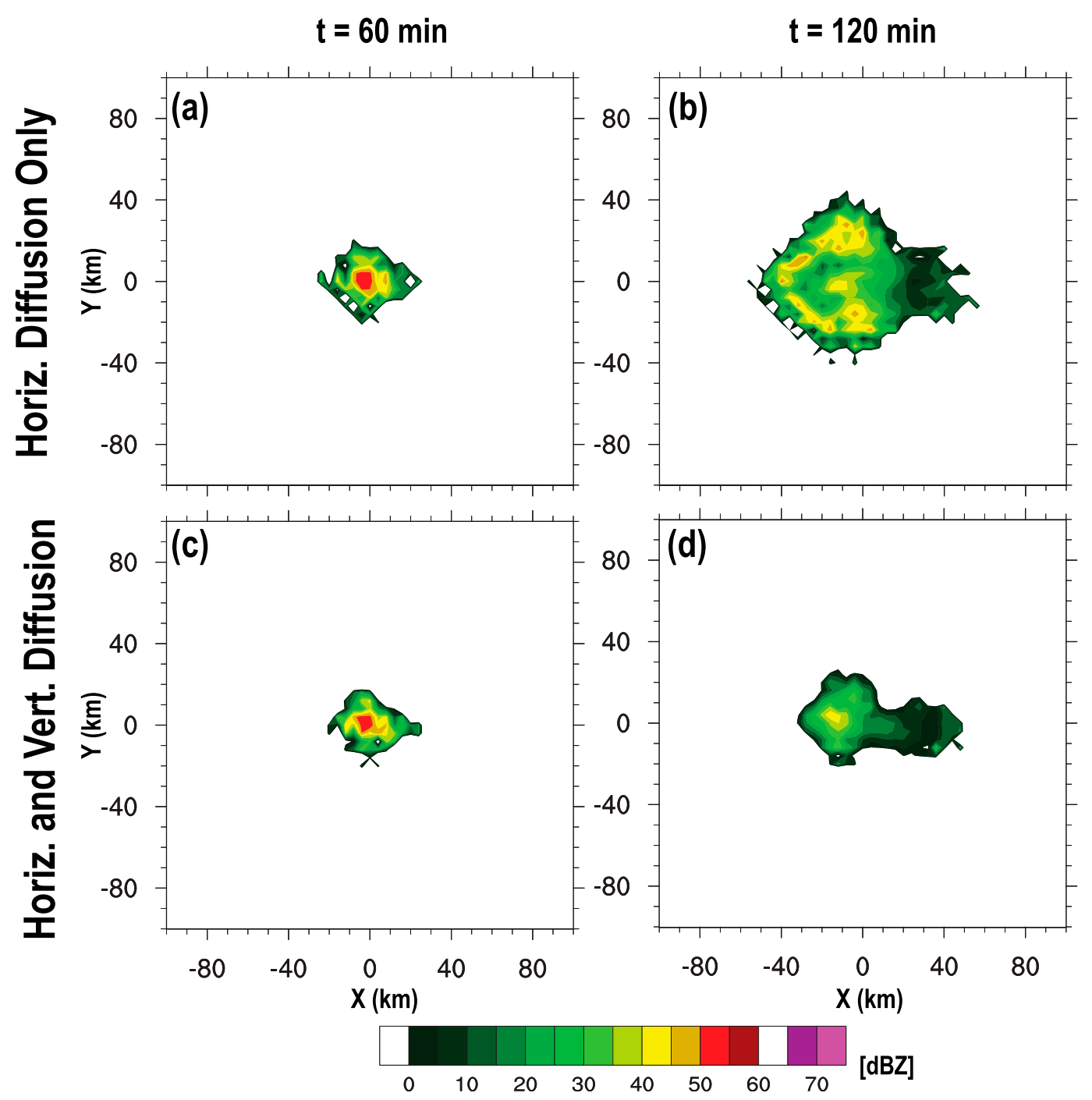

FIG. 9. Horizontal cross sections of reflectivity at $525 \mathrm{~m} \mathrm{AGL}$ at (a),(c) $t=60 \mathrm{~min}$ and (b),(d) $t=120 \mathrm{~min}$ for the (top) explicit horizontal diffusion only and (bottom) explicit horizontal and vertical diffusion CM1 simulations of the NAM CONUS CI point in southern Florida.

condensate also is smoother in the simulation with explicit vertical diffusion.

The presence or absence of explicit vertical diffusion not only impacts the vertical profiles of momentum, condensate, and thermodynamics, but also impacts the evolution of the convective storms. The convective cell that develops within the first hour in the simulation lacking explicit vertical diffusion is able to initiate a ring of convection on its western side at $t=2 \mathrm{~h}$, with $0.5-\mathrm{km}$ reflectivity values of $45-50 \mathrm{~dB} Z$ (Fig. 9). In contrast, the initial cell at $t=1 \mathrm{~h}$ in the simulation with explicit vertical diffusion weakens by $t=2 \mathrm{~h}$, and no new convection develops around it. This result suggests that insufficient explicit vertical diffusion may impact the simulation of storm size, longevity, and precipitation.
Large differences also are evident in the temperature, areal coverage, and vertical depth of the cold pools that develop in the CM1 simulations with and without explicit vertical diffusion owing in part to the differences in storm evolution. Starting at $t=70 \mathrm{~min}$, the western side of the cold pool is notably colder and taller in the simulation without explicit vertical diffusion. As time progresses, this cold pool remains taller, colder, and spreads laterally at a faster rate than seen from the cold pool in the simulation with explicit vertical diffusion. By $t=120 \mathrm{~min}$, the diameter of the cold pool in the simulation without explicit vertical diffusion is about $120 \mathrm{~km}$, whereas the cold pool diameter is only $100 \mathrm{~km}$ in the simulation with explicit vertical diffusion (Fig. 10). Furthermore, the cold pool is about $4^{\circ} \mathrm{C}$ colder in the 


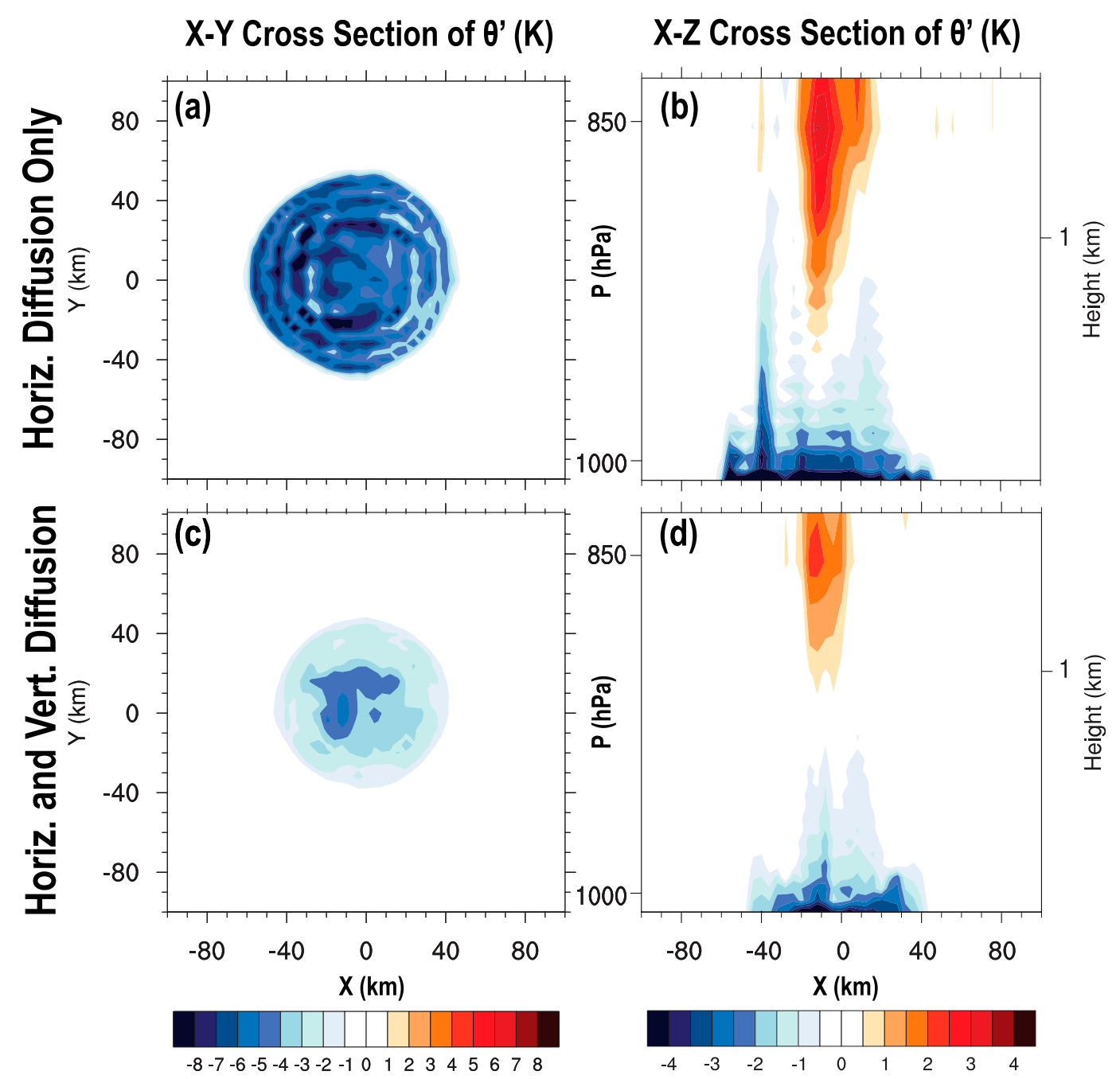

FIG. 10. The (left) $X-Y$ and (right) $X-Z$ cross sections of $\theta^{\prime}$ at the lowest model level at $t=120 \mathrm{~min}$ for the (a),(b) explicit horizontal diffusion only and (c),(d) explicit horizontal and vertical diffusion CM1 simulations of the NAM CONUS CI point in southern Florida. The $X-Z$ cross section is located along $Y=0$.

simulation without explicit vertical diffusion. The warm anomaly at the base of the updraft is also wider and a few degrees Celsius warmer in the run without explicit vertical diffusion.

Running CM1 with or without explicit vertical diffusion also leads to differences in storm structure when initializing the model with the Weisman and Klemp (1982) supercell sounding, although the differences are subtle. Aside from the run without explicit vertical diffusion being $5 \mathrm{~min}$ faster with the initiation of convection, both simulations produce splitting supercells within the first $1.5 \mathrm{~h}$ and have model reflectivity fields that remain qualitatively similar throughout the first two hours. After two hours, minor differences are noted on the western, or upshear side of the supercells, where lower reflectivity values are depicted in the run with explicit vertical diffusion. Differences also develop in the model cold pools. Many parts of the cold pool are $1-2 \mathrm{~K}$ warmer in the simulation with explicit vertical diffusion at $t=3 \mathrm{~h}$ (Fig. 11). Furthermore, the areas of the cold pool underneath both the right and left moving supercells exhibit more of a wavelike structure in the simulation lacking explicit vertical diffusion, with equally spaced local maxima and minima in perturbation potential temperature $\theta^{\prime}$ (Fig. 11). These waves are similar to those seen in the CM1 simulation using the NAM sounding without explicit vertical diffusion (Fig. 10a). Vertical soundings from the supercell simulation without explicit vertical diffusion show noisy vertical thermodynamic profiles similar to those seen in Fig. 8c, which become smooth when explicit vertical diffusion is active similar to Fig. 8f. 
0.5 km Reflectivity (dBZ)

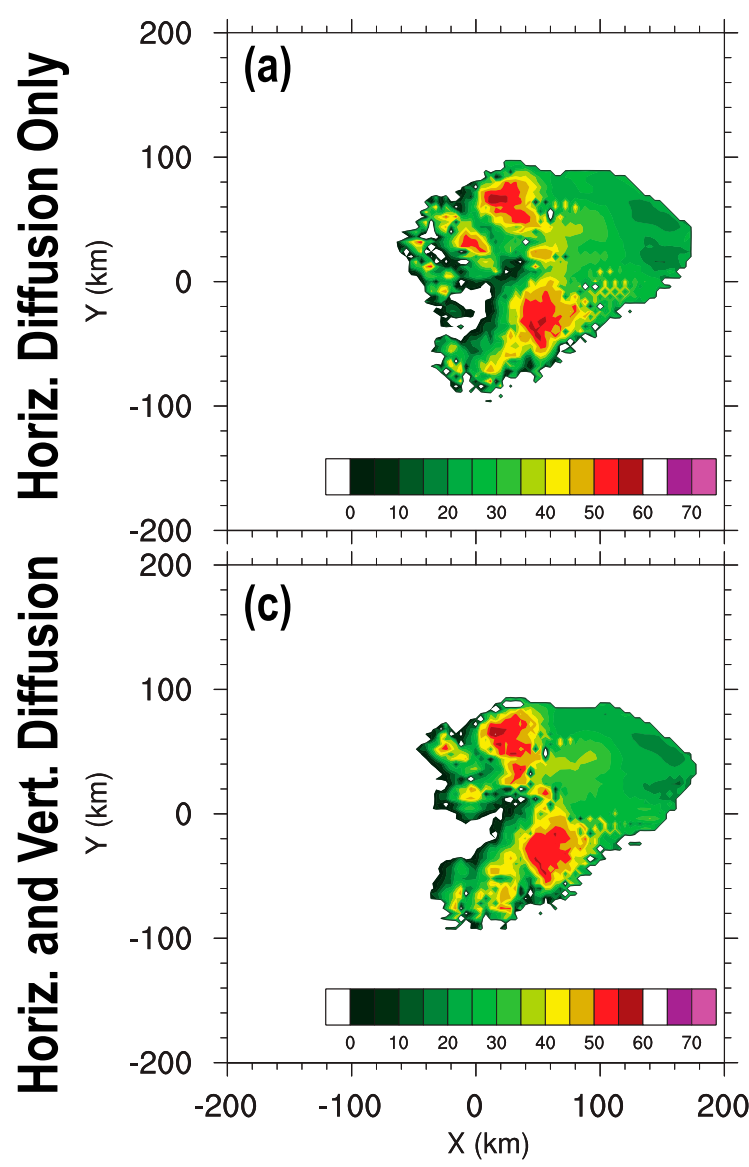

$\theta^{\prime}$ at Lowest Level (K)

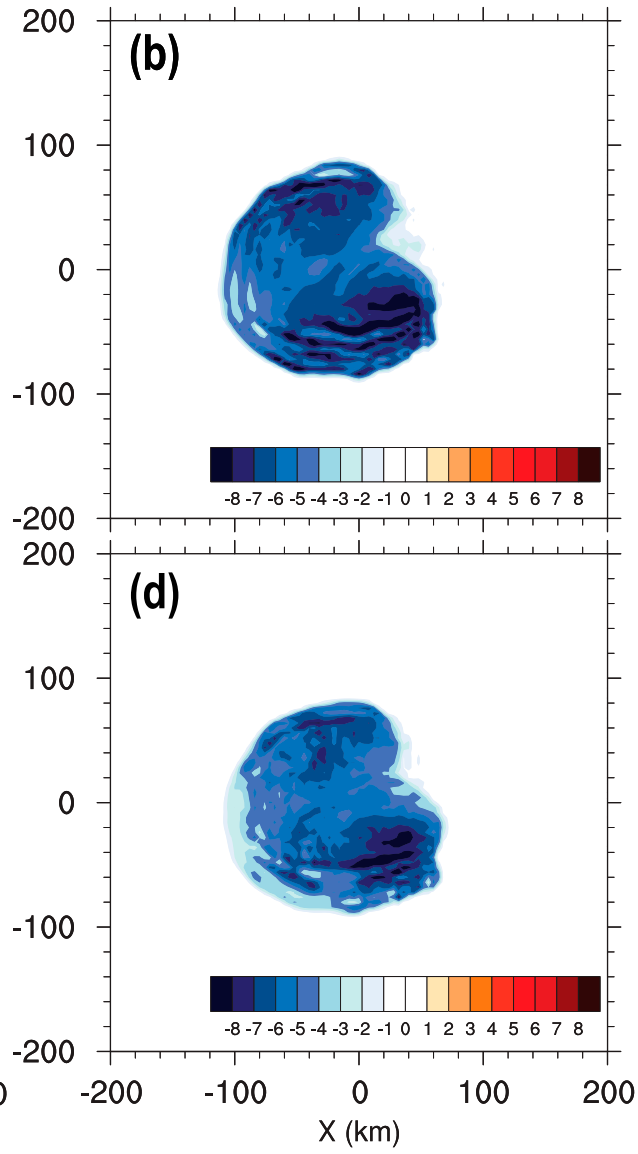

\section{Difference Fields}

(Horiz. and Vert. Diffusion - Horiz. Diffusion Only)

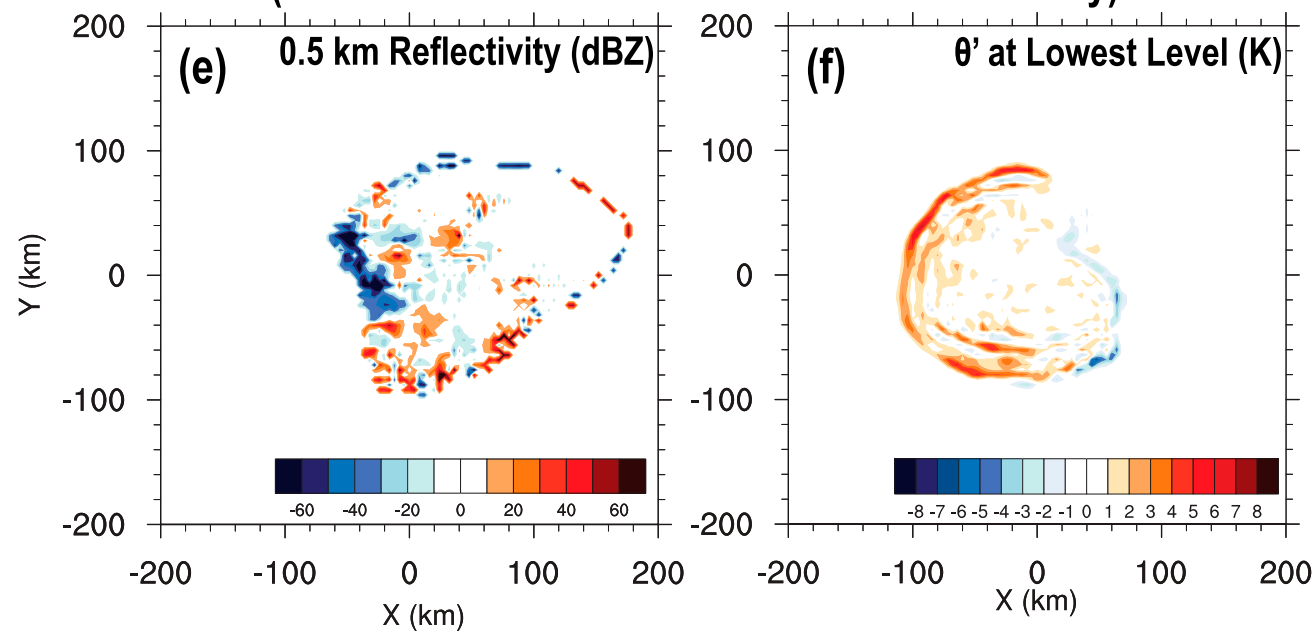

FIG. 11. (a),(c) Model reflectivity at $500 \mathrm{~m}$, (b),(d) $\theta^{\prime}$ at the lowest model level, and the differences in (e) reflectivity and (f) $\theta^{\prime}$ at $t=3 \mathrm{~h}$ from the CM1 simulations using the Weisman and Klemp supercell sounding. Results from (top) the simulation with only explicit horizontal diffusion, (middle) the simulation with both explicit horizontal and vertical diffusion, and (bottom) differences for the run with explicit horizontal and vertical diffusion minus the run with explicit horizontal diffusion. 
The 4-h accumulated rainfall in the idealized supercell simulations also differs depending on whether explicit vertical diffusion is included in the model (Fig. 12). The most notable difference in the accumulated rainfall field is near the track of the right mover, where more than $10 \mathrm{~cm}$ of rainfall accumulates over $4 \mathrm{~h}$ in the simulation without explicit vertical diffusion, roughly $50 \%$ more than the rainfall totals in the simulation with both explicit horizontal and vertical diffusion. Most of this excess rainfall can be attributed to the higher rainfall rates after $t=2 \mathrm{~h}$ (recall the areas of higher reflectivity on the upshear side of the supercells). Additionally, new cells develop to the southwest of the right moving supercell in the run without explicit vertical diffusion after $t=3 \mathrm{~h}$.

Differences in the 0-3-km updraft helicity (UH; Kain et al. 2008) swaths are unremarkable in the first three hours of the simulations, after which only small differences are found depending on whether or not explicit vertical diffusion is included (Figs. 12b,d,f). Local maxima of UH exceeding $200 \mathrm{~m}^{2} \mathrm{~s}^{-2}$ are found farther southeast in the simulation without explicit vertical diffusion, collocated with cells developing after three hours. However, UH values in excess of $150 \mathrm{~m}^{2} \mathrm{~s}^{-2}$ associated with the primary right moving supercell extend farther southeast in the run with both explicit horizontal and vertical diffusion. Differences in storm location only become apparent several hours into the model run, as the difference in storm motion of the right-moving supercells between the two runs is less than $1 \mathrm{~m} \mathrm{~s}^{-1}$ and $1^{\circ}$, where the motion of the storm in the simulation with both explicit horizontal and vertical diffusion is just slightly faster with a track turned only slightly toward the north.

Finally, the Advanced Research WRF (ARW) Model is run for an idealized supercell thunderstorm case that uses the Weisman-Klemp (Weisman and Klemp 1982) analytic sounding and a quarter circle hodograph to construct the environment. Results without explicit vertical diffusion (not shown) again resemble those seen in the NAM and CM1, namely that as the MAUL associated with the updraft moves upward, the $\theta_{e}$ values within the MAUL are larger than the $\theta_{e}$ values associated with the moist adiabat that represents the rising parcel when explicit vertical diffusion is neglected. However, the downward propagating waves of alternating $\theta_{e}$ anomalies are not seen in the WRF runs. Just a single upward moving $\theta_{e}$ anomaly associated with the updraft is seen. When explicit horizontal and vertical diffusion is used, however, this rising anomalous $\theta_{e}$ anomaly disappears as seen in CM1. The consistent behaviors seen from the CM1 and ARW results indicate that the noisy vertical profiles found in the NAM can occur in other numerical models depending upon the approaches used for representing explicit diffusion.
Although the differences in model fields from the idealized supercell simulations with and without explicit vertical diffusion are subtle, they are not negligible. As shown, spurious convection developing upstream can dramatically increase simulated rainfall totals, a model field that forecasters routinely use in flash flood forecasting. Differences in the magnitude and distribution of cold air within the cold pool can impact a storm's ability to produce a downdraft or a vertical vortex near the ground. The idealized storm motions are different, yielding earlier or later times of arrival of hazardous weather at a given location and in a real-time application this could potentially influence when warnings are issued. Ensembles of simulations without explicit vertical diffusion may have greater variation, leading to increased ensemble spread and impacting the predictability of these events. The Weisman and Klemp supercell sounding contains vertical temperature and wind gradients that are generally much smoother than those found in most numerical models and in nature. Thus, it is probable that larger differences between the storms simulated with and without explicit vertical diffusion would arise when using thermodynamic profiles with larger vertical gradients, although whether or not these differences would degrade forecast skill is uncertain.

\section{Conclusions}

In examining the processes leading to $\mathrm{CI}$ in the NAM CONUS and Fire Weather nests, a repeatable pattern of evolution is found. Preexisting upward motion at low levels enables warm parcels to rise to their LFC. As the buoyancy force accelerates the rising parcels upward, the depth and magnitude of the upward motion increases, and a MAUL forms at the top of the updraft. In many cases, particularly when strong updrafts coexist with large vertical gradients of potential temperature and moisture, noisy profiles of temperature, moisture, and hydrometeors develop beneath this rising MAUL and extend downward. The noisy profiles found in this study are qualitatively similar to those discussed by Ferrier et al. (2017), which are known to be responsible for failures in the NAMv3.

By configuring CM1 to replicate the NAM numerical set up as closely as possible, and using an appropriate NAM sounding, we found that these noisy vertical profiles develop when explicit vertical diffusion is insufficient. The presence of noisy vertical profiles leads to the development of nearby spurious convection, as well as altering the depth, size, and magnitude of cold pools, and other storm attributes including updraft helicity and precipitation. Although these noisy thermodynamic profiles are removed in NAMv4 by stabilizing 

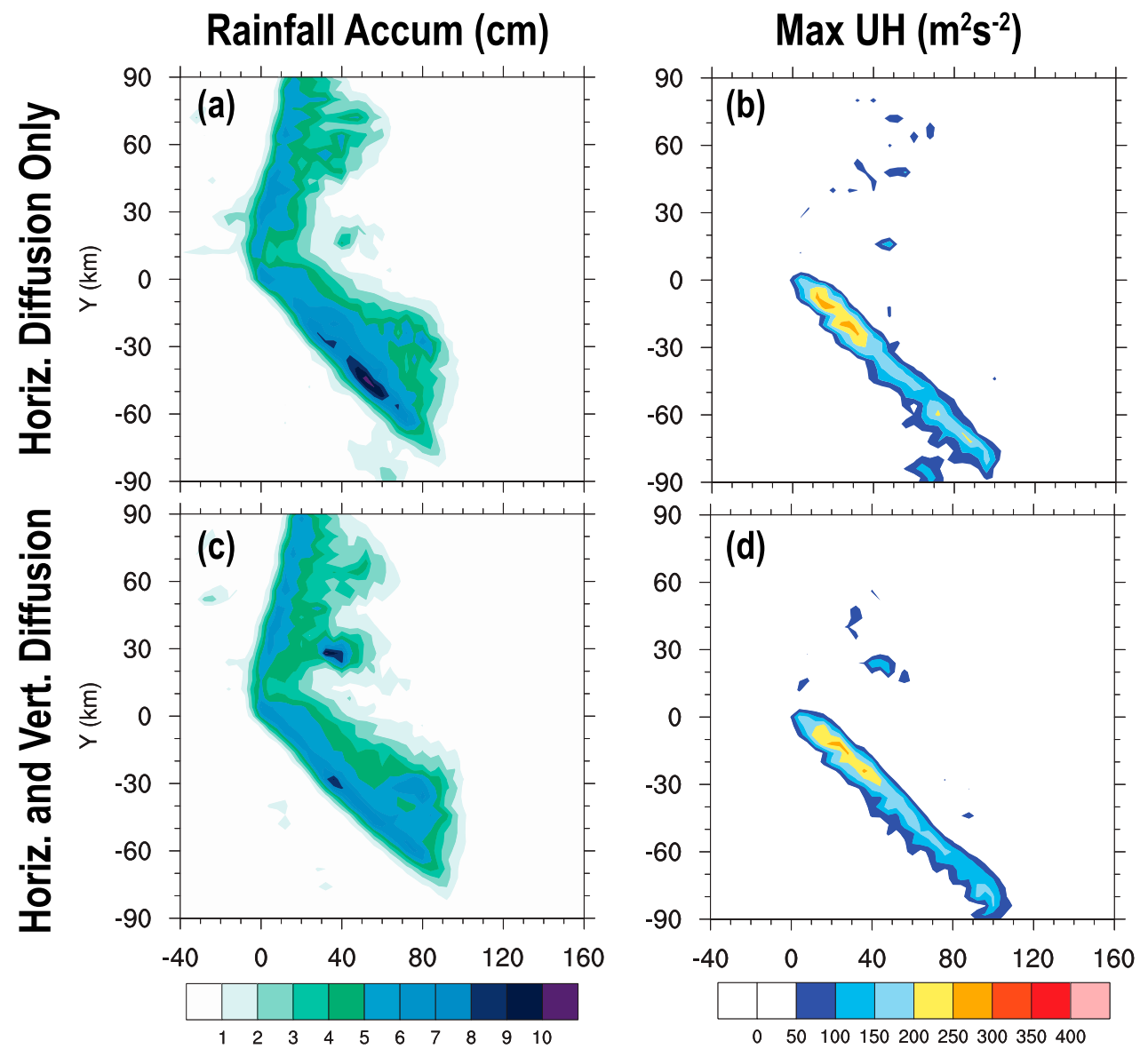

\section{Difference Fields}

(Horiz. and Vert. Diffusion - Horiz. Diffusion Only)
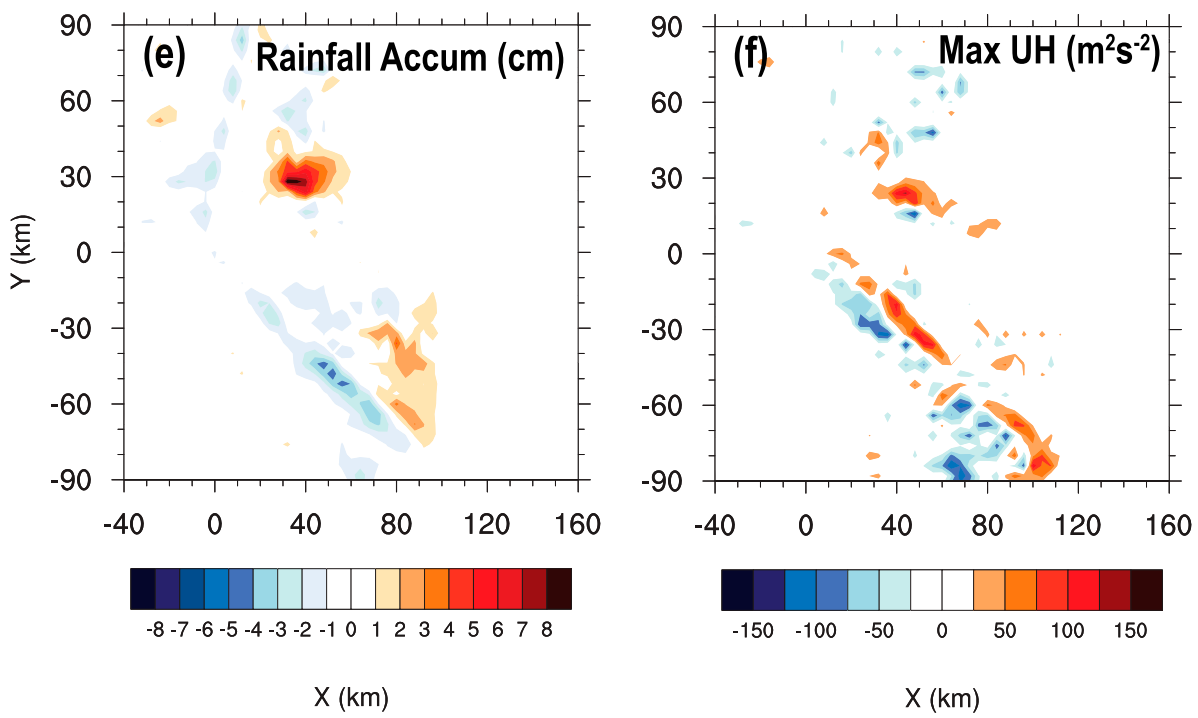

FIG. 12. (a),(c) Model run accumulated rainfall, (b),(d) maximum 0-3-km updraft helicity, and (e),(f) their differences over the course of the 4-h CM1 simulations using the Weisman and Klemp supercell sounding. Results from (top) the simulation with only explicit horizontal diffusion, (middle) the simulation with both explicit horizontal and vertical diffusion, and (bottom) differences for the run with explicit horizontal and vertical diffusion minus the runs with explicit horizontal diffusion. 
superadiabatic layers above the surface layer (Ferrier et al. 2017), this solution is ad hoc. Insufficient explicit vertical diffusion may also contribute to model biases related to other atmospheric phenomena outside the scope of this paper, possibly including the strength of temperature inversions aloft and the mixing out of shallow moist layers near the surface.

Acknowledgments. The authors gratefully acknowledge the assistance and suggestions provided by Eli Dennis, Matt Pyle, Drs. Eric Rogers, Geoff DiMego, Brad Ferrier, Eric Aligo, Jacob Carley, and others too numerous to mention at the NOAA Environmental Modeling Center, for running the NAMv3 simulations and working closely with the authors in the summer of 2016. We are thankful for the very helpful and constructive comments of three anonymous reviewers. This work was done in support of the NOAA Next Generation Global Prediction System (NGGPS) project, award NA15NWS4680012. The 5-minute NAMv3 output from both the $4-\mathrm{km}$ and $1.33-\mathrm{km}$ grids is available from the Penn State Data Commons at http://www.datacommons.psu.edu/ commonswizard/MetadataDisplay.aspx?Dataset $=6155$.

\section{REFERENCES}

Aligo, E. A., B. Ferrier, and J. R. Carley, 2018: Modified NAM microphysics for forecasts of deep convective storms. Mon. Wea. Rev., 146, 4115-4153, https://doi.org/10.1175/MWR-D17-0277.1.

Benjamin, S. G., S. Weygandt, C. Alexander, J. M. Brown, T. G. Smirnova, P. Hofmann, E. James, and G. Dimego, 2011: NOAA's hourly-updated $3 \mathrm{~km}$ HRRR and RUC/Rapid Refresh-Recent (2010) and upcoming changes toward improving weather guidance for air-traffic management. Second Aviation, Range, and Aerospace Meteorology Special Symp. on Weather-Air Traffic Management Integration, Seattle, WA, Amer. Meteor. Soc., 3.2, https://ams.confex.com/ams/91Annual/webprogram/ Paper185659.html.

Bryan, G. H., and J. M. Fritsch, 2000: Moist absolute instability: The sixth static stability state. Bull. Amer. Meteor. Soc., 81, 1207-1230, https://doi.org/10.1175/1520-0477(2000)081<1287: MAITSS $>2.3 . \mathrm{CO} ; 2$.

— , and — 2002: A benchmark simulation for moist nonhydrostatic numerical models. Mon. Wea. Rev., 130, 2917-2928, https://doi.org/10.1175/1520-0493(2002)130<2917:ABSFMN> 2.0.CO;2.

Burghardt, B. J., C. Evans, and P. J. Roebber, 2014: Assessing the predictability of convection initiation in the High Plains using an object-based approach. Wea. Forecasting, 29, 403-418, https://doi.org/10.1175/WAF-D-13-00089.1.

Burlingame, B. M., C. Evans, and P. J. Roebber, 2017: The influence of PBL parameterization on the practical predictability of convection initiation during the Mesoscale Predictability Experiment (MPEX). Wea. Forecasting, 32, 1161-1183, https://doi.org/10.1175/WAF-D-16-0174.1.

Clark, A. J., W. A. Gallus Jr., M. Xue, and F. Kong, 2009: A comparison of precipitation forecast skill between small convection-allowing and large convection-parameterizing ensembles. Wea. Forecasting, 24, 1121-1140, https://doi.org/10.1175/ 2009WAF2222222.1.

Done, J., C. Davis, and M. Weisman, 2004: The next generation of NWP: Explicit forecasts of convection using the Weather Research and Forecasting (WRF) model. Atmos. Sci. Lett., 5, 110-117, https://doi.org/10.1002/asl.72.

Duda, J. D., and W. A. Gallus, 2013: The impact of large-scale forcing on skill of simulated convective initiation and upscale evolution with convection-allowing grid spacings in the WRF. Wea. Forecasting, 28, 994-1018, https://doi.org/10.1175/WAFD-13-00005.1.

Eckermann, S., 2009: Hybrid $\sigma-$ p coordinate choices for a global model. Mon. Wea. Rev., 137, 224-245, https://doi.org/10.1175/ 2008MWR2537.1.

Ek, M. B., K. E. Mitchell, Y. Lin, E. Rogers, P. Grunmann, V. Koren, G. Gayno, and J. D. Tarpley, 2003: Implementation of Noah land surface model advances in the National Centers for Environmental Prediction operational mesoscale Eta model. J. Geophys. Res., 108, 8851, https://doi.org/10.1029/ 2002JD003296.

Ferrier, B. S., Z. Janjić, E. Aligo, D. Jovic, E. Roger, J. R. Carley, M. Pyle, and G. J. DiMego, 2017: NMMB model changes as part of the NAMv4 upgrade. 28th Conf. on Weather Analysis and Forecasting/24th Conf. on Numerical Weather Prediction, Seattle, WA, Amer. Meteor. Soc., 1205, https://ams.confex.com/ ams/97Annual/webprogram/Paper312628.html.

Fowle, M. A., and P. J. Roebber, 2003: Short-range (0-48 h) numerical prediction of convective occurrence, mode, and location. Wea. Forecasting, 18, 782-794, https://doi.org/10.1175/ 1520-0434(2003)018<0782:SHNPOC $>2.0$. CO;2.

Gremillion, M. S., and R. E. Orville, 1999: Thunderstorm characteristics of cloud-to-ground lightning at the Kennedy Space Center, Florida: A study of lightning initiation signatures as indicated by the WSR-88D. Wea. Forecasting, 14, 640-649, https://doi.org/10.1175/1520-0434(1999)014<0640:TCOCTG> 2.0.CO;2.

Iacono, M. J., J. S. Delamere, E. J. Mlawer, M. W. Shephard, S. A. Clough, and W. D. Collins, 2008: Radiative forcing by longlived greenhouse gases: Calculations with the AER radiative transfer models. J. Geophys. Res., 113, D13103, https://doi.org/ 10.1029/2008JD009944.

Janjić, Z., 1990: The step-mountain coordinate: Physical package. Mon. Wea. Rev., 118, 1429-1443, https://doi.org/10.1175/1520-0493(1990) $118<1429$ :TSMCPP $>2.0$. .CO;2.

, 1994: The step-mountain eta coordinate model: Further developments of the convection, viscous sublayer, and turbulence closure schemes. Mon. Wea. Rev., 122, 927-945, https:// doi.org/10.1175/1520-0493(1994)122<0927:TSMECM> 2.0.CO;2.

— , and R. Gall, 2012: Scientific documentation of the NCEP nonhydrostatic multiscale model on the B grid (NMMB). Part 1 Dynamics. NCAR Tech. Note NCAR/TN-489+STR, https:// doi.org/10.5065/D6WH2MZX.

, T. L. Black, M. E. Pyle, H.-Y. Chuang, E. Rogers, and G. J. DiMego, 2005: The NCEP WRF-NMM core. Preprints, Joint WRF/MM5 User's Workshop, Boulder, CO, NCAR, 2.9, http://www2.mmm.ucar.edu/wrf/users/workshops/WS2005/ presentations/session2/9-Janjic.pdf.

Kain, J. S., S. J. Weiss, J. J. Levit, M. E. Baldwin, and D. R. Bright, 2006: Examination of convection-allowing configurations of the WRF model for the prediction of severe convective weather: The SPC/NSSL Spring Program 2004. Wea. Forecasting, 21, 167-181, https://doi.org/10.1175/WAF906.1. 
and Coauthors, 2008: Some practical considerations regarding horizontal resolution in the first generation of operational convection-allowing NWP. Wea. Forecasting, 23, 931-952, https:// doi.org/10.1175/WAF2007106.1.

—_, and Coauthors, 2013: A feasibility study for probabilistic convection initiation forecasts based on explicit numerical guidance. Bull. Amer. Meteor. Soc., 94, 1213-1225, https:// doi.org/10.1175/BAMS-D-11-00264.1.

Lane, T. P., R. D. Sharman, T. L. Clark, and H. Hsu, 2003: An investigation of turbulence generation mechanisms above deep convection. J. Atmos. Sci., 60, 1297-1321, https://doi.org/ 10.1175/1520-0469(2003)60<1297:AIOTGM>2.0.CO;2.

Lean, H. W., P. A. Clark, M. Dixon, N. M. Roberts, A. Fitch, R. Forbes, and C. Halliwell, 2008: Characteristics of highresolution versions of the Met Office Unified Model for forecasting convection over the United Kingdom. Mon. Wea. Rev., 136, 3408-3424, https://doi.org/10.1175/2008MWR2332.1.

Lock, N. A., and A. L. Houston, 2014: Empirical examination of the factors regulating thunderstorm initiation. Mon. Wea. Rev., 142, 240-258, https://doi.org/10.1175/MWR-D13-00082.1.

Loftus, A. M., D. B. Weber, and C. A. Doswell, 2008: Parameterized mesoscale forcing mechanisms for initiating numerically simulated isolated multicellular convection. Mon. Wea. Rev., 136, 2408-2421, https://doi.org/10.1175/2007MWR2133.1.

Mecikalski, J. R., and K. M. Bedka, 2006: Forecasting convective initiation by monitoring the evolution of moving cumulus in daytime GOES imagery. Mon. Wea. Rev., 134, 49-78, https:// doi.org/10.1175/MWR3062.1.

Mlawer, E. J., S. J. Taubman, P. D. Brown, M. J. Iacono, and S. A. Clough, 1997: Radiative transfer for inhomogeneous atmospheres: RRTM, a validated correlated-k model for the longwave. J. Geophys. Res., 102, 16 663-16 682, https://doi.org/ 10.1029/97JD00237.

Morrison, H., J. A. Curry, M. D. Shupe, and P. Zuidema, 2005: A new double-moment microphysics parameterization for application in cloud and climate models. Part II: Single-column modeling of arctic clouds. J. Atmos. Sci., 62, 1678-1693, https:// doi.org/10.1175/JAS3447.1.

-, G. Thompson, and V. Tatarskii, 2009: Impact of cloud microphysics on the development of trailing stratiform precipitation in a simulated squall line: Comparison of one- and two-moment schemes. Mon. Wea. Rev., 137, 991-1007, https:// doi.org/10.1175/2008MWR2556.1.

NEMS-NMMB, 2016: Community NEMS-NMMB users' guide V1.0. Developmental Testbed Center, 91 pp., http://www.dtcenter.org/ nems-nmmb/users/tutorial/nmmb_users_guide.pdf.

Roberts, N. M., and H. W. Lean, 2008: Scale-selective verification of rainfall accumulations from high-resolution forecasts of convective events. Mon. Wea. Rev., 136, 78-97, https://doi.org/ 10.1175/2007MWR2123.1.

Roberts, R. D., and S. Rutledge, 2003: Nowcasting storm initiation and growth using GOES-8 and WSR-88D data. Wea. Forecasting, 18, 562-584, https://doi.org/10.1175/1520-0434(2003) $018<0562$ :NSIAGU $>2.0 . \mathrm{CO} ; 2$.

Skamarock, W. C., and Coauthors, 2008: A description of the Advanced Research WRF version 3. NCAR Tech. Note NCAR/ TN-475+STR, 113 pp., https://doi.org/10.5065/D68S4MVH.

Smagorinsky, J., 1963: General circulation experiments with the primitive equations. Mon. Wea. Rev., 91, 99-164, https:// doi.org/10.1175/1520-0493(1963)091<0099:GCEWTP > 2.3. $\mathrm{CO} ; 2$.

Snively, D. V., and W. A. Gallus, 2014: Prediction of convective morphology in near-cloud-permitting WRF model simulations. Wea. Forecasting, 29, 130-149, https://doi.org/10.1175/ WAF-D-13-00047.1.

Sobash, R. A., J. S. Kain, D. R. Bright, A. R. Dean, M. C. Coniglio, and S. J. Weiss, 2011: Probabilistic forecast guidance for severe thunderstorms based on the identification of extreme phenomena in convection-allowing model forecasts. Wea. Forecasting, 26, 714-728, https://doi.org/10.1175/WAF-D-1005046.1

Weisman, M. L., and J. B. Klemp, 1982: The dependence of numerically simulated convective storms on vertical wind shear and buoyancy. Mon. Wea. Rev., 110, 504-520, https://doi.org/ 10.1175/1520-0493(1982)110<0504:TDONSC >2.0.CO;2.

_ C. Davis, W. Wang, K. W. Manning, and J. B. Klemp, 2008: Experiences with 0-36-h explicit convective forecasts with the WRF-ARW model. Wea. Forecasting, 23, 407-437, https:// doi.org/10.1175/2007WAF2007005.1.

Ziegler, C. L., and E. N. Rasmussen, 1998: The initiation of moist convection at the dryline: Forecasting issues from a case study perspective. Wea. Forecasting, 13, 1106-1131, https://doi.org/ 10.1175/1520-0434(1998)013<1106:TIOMCA > 2.0.CO;2. 